\title{
Estado da arte de pesquisas sobre problemas de comportamento no contexto escolar
}

\section{Resumo}

Nilza Sanches Tessaro Leonardo Záira Fátima de Rezende Gonzalez Leal Solange Pereira Marques Rossato Universidade Estadual de Maringá

A queixa escolar, relacionada aos problemas de comportamento apresentados pelas crianças e adolescentes, é frequentemente associada a um problema de saúde, em uma individualização dos problemas. Com base nessa constatação, este trabalho teve por objetivo analisar artigos que versavam sobre problemas de comportamento, publicados em periódicos científicos, entre os anos de 1990 e 2014, identificando as concepções circunscritas nesses periódicos. Foram realizadas pesquisas em bancos de dados e indexadores e, sobre o tema em questão, selecionando os artigos referentes à área da Psicologia e Educação, resultando em um total de 47 textos. A análise e discussão se fundamentaram na Psicologia HistóricoCultural. Os resultados apontam que, em 72,4\% dos artigos, os problemas de comportamento são compreendidos como centrado no indivíduo, desvinculando-os da totalidade que envolve o processo de escolarização, da sociedade em que é produzido, do modo de produção que impera, realizando, assim, uma análise reducionista e limitada do fenômeno.

Palavras-chave: Psicologia Histórico-Cultural. Problemas de comportamento. Queixa escolar. Educação.

\section{State of the art of research on behavior problems in the school context}

\begin{abstract}
The school complaint related to behavioral problems presented by children and adolescents is often associated with a health problem, in an individualization of problems. Based on this finding, this work had as objective to analyze articles that dealt with behavioural problems, published in scientific periodicals, between the years of 1990 and 2014 , identifying the conceptions circumscribed in these journals. Researches were carried out in data banks and indexers and, on the subject in question, selecting the articles referring to the area of Psychology and Education, resulting in a total of 47 texts. The analysis and discussion were based on the Historical-Cultural Psychology. The results indicate that, in72,4\% of the articles, behavioral problems are understood as centered on the individual, dissociating them from the totality involved in the schooling process, the society in which it is produced, the mode of production that prevails, thus carrying out a reductionist and limited analysis of the phenomenon.

Keywords: Historical-Cultural Psychology. Behavior problems. School complaint. Education.
\end{abstract}




\section{Estado del arte de las investigaciones sobre los problemas de comporta- miento en el contexto escolar}

\section{Resumen}

La queja escolar relacionada con los problemas de comportamiento presentados por niños y adolescentes es frecuentemente asociada a un problema de salud, en una individualización de los problemas. Con base en esta constatación, este trabajo tuvo por objetivo analizar artículos que versaban académicamente sobreproblemas de comportamiento, publicados en periódicos científicos, entre los años 1990 y 2014 , identificando las concepciones circunscritas en estos periódicos. Se realizaron investigaciones en bancos de datos y indexadores y, sobre el tema en cuestión, seleccionando los artículos referentes al área de Psicología y Educación, resultando en un total de 47 textos. El análisis y discusión se fundamentaron en la Psicología Histórico-Cultural. Los resultados apuntan que, en el 72,4\% de los artículos, los problemas de comportamiento son comprendidos como centrado en el individuo, desvinculándolos de la totalidad que implica el proceso de escolarización, de la sociedad en que se produce y del modo de producción que impera, realizando así un análisis reduccionista y limitado del fenómeno.

Palabras clave: Psicología Histórico-Cultural. Problemas de comportamiento. Queja escolar. Educación.

\section{Introdução}

AVive-se numa sociedade e num período histórico em que predomina o sistema de contradições e desigualdades sociais, culturais e econômicas, próprias ao modo capitalista de produção que configura nossa sociedade. Nesse contexto de desigualdades, como afirmam Garrido e Moysés (2010), os que possuem a riqueza também detêm o controle das ideias que explicam a sociedade e, portanto, o controle sobre a classificação das pessoas e o julgamento sobre o outro. Detêm o poder sobre o processo de nomeação e de enquadre do que se entende por problema, por desvio dos considerados padrões de conduta, de aprendizagem, de desenvolvimento etc. Esse processo contribui para o discurso de naturalização das desigualdades socialmente produzidas, avalizadas pela explicação de que a sua origem está localizada no indivíduo, por suas inapropriadas condições. Neste contexto, nega-se a história de disparidades de possibilidades de apropriação dos bens culturais e econômicos, tratando as distinções individuais e desigualdades sociais como se fossem causa e consequência. 
Não obstante o predomínio de tais explicações, alicerçadas pela Psicologia Histórico-Cultural, por uma perspectiva crítica de psicologia, enfatiza-se que o desenvolvimento do homem e suas conquistas estão em estreitas relações e dependência do seu acesso à universalização cultural, constituída historicamente. Assim, quanto maiores forem as discrepâncias das condições sociais, culturais, econômicas, maiores serão as diferenças no desenvolvimento individual, constituindo-se, portanto, em uma relação dialética entre universal e individual. Assim, pode-se dizer que a desigualdade de distribuição da riqueza material também configura na distribuição do conhecimento, visando conformar e manter a distância entre os detentores do poder e os dominados, considerando que, no modo de produção capitalista, as classes sociais que a compõem têm acesso aos bens culturais de forma desigual.

Como indicam Klein, Silva e Mata (201 1, p. 250), há uma precária formação humana em razão do sistema capitalista alienar "[...] a maior parte das pessoas das potencialidades conquistadas socialmente". A formação humana está, portanto, aliada às possibilidades de aquisição e de apropriação do que há no universal, que constitui e confere ao homem suas especificidades ao longo do seu desenvolvimento histórico-social.

Essas possibilidades têm a educação escolar como mediadora e socializadora em relação ao universal. Assim, a educação escolar é essencial na formação dos sujeitos, no desenvolvimento de suas funções psicológicas superiores (memória, atenção voluntária, percepção, pensamento abstrato, vontade ou volição etc.), de suas capacidades, na aquisição de significações, de costumes, de conhecimentos, enfim, das propriedades que the conferem a condição de ser humano e de criar, constantemente, outras necessidades.

Nesse aspecto, Aita e Facci (201 1, p. 1), ao discutirem sobre a constituição humana e a importância da educação escolar nesse processo, identificam que se o homem não nasce pronto, ou seja, " [...] dotado de todas as características que o faz homem, a educação é destacada enquanto meio pelo qual este homem apropria-se da cultura e se desenvolve enquanto ser humano". Então, pode-se encontrar, na educação, quando devidamente organizada, as mediações para formar um indivíduo que, além de apenas reproduzir a sociedade, poderá também transformar-se e transformá-la. Neste sentido, Saviani (2007, p. 154) afirma que "[...] a origem da educação coincide $[\ldots]$ com a origem do homem mesmo". 
indivíduo, nessa perspectiva, não se faz humano naturalmente; ao contrário, ele produz a sua existência e da sociedade por meio de um processo educativo, imerso em suas relações sociais, em atividade, no trabalho. "A partir desta concepção de constituição social do homem, nota-se a importância da escola no processo de humanização" (AITA; FACCl, 201 1, p. 1).

É a apropriação dos conhecimentos científicos, conforme discute Facci (2004), que possibilita o desenvolvimento das funções psicológicas superiores. Portanto, é preciso considerar e avaliar as condições que possibilitaram ou não o desenvolvimento, a prática social em que se desenvolve a prática educativa, que podem levar, em seu conjunto, ao sucesso e ao insucesso escolar, sendo eles alavancados por múltiplas relações e determinações.

A educação escolar contribui para os processos de aquisição do conhecimento, do desenvolvimento das condutas humanas, ao mesmo tempo que reflete o desenvolvimento, as contradições, as relações de poder, as características prementes na sociedade. Assim, deve se constituir, portanto, para além de mediadora do conhecimento, exercendo a reflexão e a crítica, em uma leitura que supere o aparente, o que se coloca como naturalmente dado, como se pode verificar em relação aos comportamentos considerados pro40 blemas, os quais são apontados, geralmente, como inadequação dos alunos pobres no processo de ensino e aprendizagem.

A educação escolar tem sido destacada sob o mote de "educação para todos", vislumbrando a universalização do acesso, o qual tem se efetivado com avanços significativos no número de matrículas no ensino fundamental. Entretanto, o fato de "quase todas" as crianças de 6 a 14 anos estarem nas escolas, verificados pelos $99 \%$ dos pertencentes às famílias mais ricas e os 97\% dos mais pobres (ANUÁRIO BRASILEIRO DE EDUCAÇÃO BÁSICA, 2017), não garante a aprendizagem, o desenvolvimento, a humanização (essencialmente dos mais pobres), assim não significa oportunidades iguais de escolarização para todos e qualidade do ensino. Ainda não se pode esquecer dos 2,5 milhões de brasileiros fora da educação básica.

Pensar em passos básicos, na concretização da qualidade de ensino remete, entre outras coisas, aos conhecimentos fundamentais vinculados ao processo de alfabetização, que, no Brasil, é verificado com base no domínio da leitura, da escrita e da matemática, por meio da Avaliação Nacional de Alfabetização (ANA), cujos dados de 2014 demonstram que 45\% das 
crianças com nível socioeconômico (NSE) muito baixo apresentam proficiência em leitura no $3^{\circ}$ ano do Ensino Fundamental da rede pública. Já, entre as crianças com NSE mais alto, 98,3\% estão no nível adequado (ANUÁRIO BRASILEIRO DE EDUCAÇÃO BÁSICA, 2017).

Nessa mesma avaliação, a matemática indica as limitações no aprendizado e desenvolvimento humano, quando se averigua que, menos da metade $(42,9 \%)$ dos alunos do $3^{\circ}$ ano do ensino fundamental, estava com proficiência adequada em matemática em 2014 . Outro aspecto preocupante é que, praticamente, um quarto das crianças $(24,3 \%)$ se encontrava no nível mais baixo dessa proficiência (ANUÁRIO BRASILEIRO DE EDUCAÇÃO BÁSICA, 2017). Essa constatação é muito mais preocupante quando são contempladas avaliações mais aprofundadas sobre se, de fato, esses domínios permitem o entendimento da realidade ou se restringem a decifrar determinados códigos, signos.

Com base nessas verificações preocupantes, vale elucidar que o desenvolvimento humano, de acordo com a Psicologia Histórico-Cultural, resulta das probabilidades concretas de existência, das relações estabelecidas com outros sujeitos na produção dos meios e bens requeridos à sua sobrevivência e ao seu desenvolvimento. À luz dessa proposição, pode-se afirmar que, para os nossos alunos, suas condutas, aprendizagens e o desenvolvimento de suas funções psicológicas superiores decorrem das relações socioculturais. Com isso, o foco do problema sobre "suas" incapacidades de aprendizagem e de comportamento passa do nível individual para o social. Nesse prisma, passam a ser inevitáveis a discussão e o olhar sobre a qualidade das mediações que a sociedade atual vem proporcionando dentro e fora da escola.

Vale destacar que, segundo Vigotskii', Luria e Leontiev (2014), é, por meio da aprendizagem, que a criança ativa suas potencialidades internas; assim, esses novos processos são incorporados ao longo do desenvolvimento e se convertem em aquisições para a criança. Isso significa dizer que, para que haja o desenvolvimento das funções psicológicas superiores, ou seja, aquelas formadas culturalmente, é essencial a aprendizagem, que aciona inúmeros processos do desenvolvimento que não poderiam ser ativados por si mesmos.

Vigotskii, Luria e Leontiev (2014, p. 1 16) esclarecem que "[...] o processo de desenvolvimento segue o de aprendizagem, que cria a área de desenvolvimento potencial". Cada coisa que é ensinada à criança passa a se relacionar, de maneira particular, com o seu desenvolvimento. Essa relação 
entre aprendizagem e desenvolvimento vai se alterando de acordo com a passagem da criança de uma etapa para outra, alavancando uma série de processos internos, bem como a totalidade de constituição do estudante. Por isso, é necessário reavaliar o papel e a importância da aprendizagem no posterior desenvolvimento psicointelectual da criança e problematizar a educação escolar (VIGOTSKII; LURIA; LEONTIEV, 2014).

Leontiev (2004) afirma que as funções psicológicas superiores e o desenvolvimento psíquico são determinados pelas relações sociais existentes e pelo lugar ocupado pelo indivíduo nessas relações, devendo ser considerados a partir de um processo de transformações qualitativas e não apenas quantitativas, pois "[...] o psiquismo humano, a consciência humana, transforma-se igualmente de maneira qualitativa no decurso do desenvolvimento histórico e social" (LEONTIEV, 2004, p. 95).

Com base nas considerações e na compreensão de homem apresentadas neste trabalho e da educação escolar enquanto fundamental no processo de humanização, justifica-se a importância deste estudo, no sentido de oferecer subsídios para a compreensão acerca dos problemas de comportamento dos alunos no contexto da educação escolar. Assim, levou-se a efeito um estudo a 42 partir de artigos científicos com o objetivo de conhecer as diferentes concepções sobre os problemas de comportamento, que compõem a temática da queixa escolar, publicados em periódicos científicos, entre os anos de 1990 e 2014. As discussões, problematizações e análises se respaldam nos fundamentos da Psicologia Histórico-Cultural.

\section{Material e método}

Para a concretização deste estudo, foi efetivada uma pesquisa de artigos sobre queixa escolar, referentes a problemas de comportamento, em bancos de dados e indexadores, como Portal da Capes, PsycINFO, LILACS, Index-Psi (BVS-PSI), entre outros, com o objetivo de verificar as concepções de problemas de comportamento apresentadas nesses artigos. Para a busca, foram utilizadas palavras-chaves, tais como: problemas de comportamento, indisciplina, queixa escolar, comportamento, hiperatividade etc. Após leitura e análise prévia dos artigos encontrados referentes ao tema, foram selecionados 47 artigos científicos, publicados entre 1990 e 2014. 
Para a análise das informações, utilizou-se a análise de conteúdo, que, conforme Chizzotti (2005, p. 98), é um método de tratamento e análise das informações, das formas como os autores configuram o social. $\bigcirc$ objetivo desse tipo de análise é "[...] compreender criticamente o sentido das comunicações, seu conteúdo manifesto ou latente, as significações explícitas ou ocultas". Vale ressaltar que, na análise de conteúdo, empregou-se, entre as técnicas possíveis, a análise categorial. Nesse caso, as concepções de problemas de comportamento, verificadas nos artigos pesquisados.

As informações obtidas por meio da leitura dos atigos foram agrupadas em dois eixos temáticos e analisadas tendo por base o referencial da Psicologia Histórico-Cultural, que compreende o homem como ser social, histórico e cultural, dotado de um psiquismo, constituído nas relações estabelecidas com a realidade social.

\section{Resultados e discussões}

Com base na leitura dos textos selecionados nos indexadores, buscou-se identificar as concepções sobre problemas de comportamento em escolares presentes nos artigos, classificando-os em dois eixos temáticos: 1) Problemas de comportamento, decorrentes de fatores individuais: a culpabilização dos alunos, da família ou dos professores; 2) Problemas de comportamento decorrentes de questões institucionais, políticas, sociais e econômicas: a não centralidade no indivíduo.

\section{Eixo 1 - Problemas de comportamento, decorrentes de fatores individuais: a culpabilização dos alunos, da família ou dos professores}

Entre as pesquisas analisadas que versam sobre a queixa escolar no que se refere aos problemas de comportamento de alunos, encontrou-se um número expressivo de textos $(72,4 \%)$ que partem do princípio de que estes são decorrentes de fatores individuais, isto é, localizam na criança, nos seus familiares e/ou professores, as causas do fenômeno. Isso evidencia que a maioria das produções científicas analisadas considera os problemas de comportamento em uma perspectiva limitada, com a qual a apreensão do fenômeno se detém em um ou outro sujeito envolvido no processo em que se produz a 
escolarização. Esses sujeitos são tomados, abstratamente, ou seja, descontextualizados de sua história escolar, social e familiar; das relações dialéticas que constituem o ensinar e o aprender; dos movimentos de vir-a-ser, próprios dos sujeitos que se inscrevem no mundo e que, se houver oportunidade, podem apropriar-se das qualidades e da riqueza da cultura humana cotidianamente.

Nessa direção, pode-se afirmar que as demandas escolares requerem que as problemáticas da vida escolar, entre elas as relativas aos comportamentos ditos "inadequados", sejam explicados em sua imediaticidade, em consonância com aquele que os detém e que, por si só, é apreciado como causa, ainda que, e contraditoriamente, sejam historicamente produzidos.

São descartadas análises mais amplas, que envolvam a incidência de fatores múltiplos na constituição dessa problemática. Assim, essa forma desvinculada de contextos mais amplos e particularizada lainda que estendida para muitos sujeitos de um mesmo grupo) de olhar para os problemas de escolarização, tem desconsiderado, principalmente, as condições sociais e econômicas da organização social capitalista que perpassam e constituem as diferentes esferas da vida, entre elas, a escolar.

A escola, sobretudo, a pública, ao se defrontar com os problemas no processo de escolarização, assume a postura de atribuir aos alunos, de forma individual, problemas que são, em sua origem, de ordem social, política e econômica, constituídos historicamente. Assim, busca-se, na maioria das vezes, no corpo da criança (em suas [in] capacidades, no funcionamento cerebral), explicações para problemas de escolarização, isentando todo o contexto escolar de sua responsabilidade. É evidente que os problemas escolares são tomados como próprios dos alunos, passando a ser vislumbrados como a expressão de todas as moléstias da escola. A escola, muitas vezes, sequer questiona a qualidade, as estratégias e métodos de ensino, o conteúdo ministrado, a relação professor/aluno/escola, e poucas vezes são consideradas as políticas públicas para a educação e a rede de relações nela imbricadas. Estaria a relação dialética ensinar/aprender contemplada e dependente apenas do sujeito do conhecimento?

Uma compreensão, nessa direção, reforça e fortalece a manutenção dos ideais neoliberais da ordem vigente, em que a responsabilização do indivíduo fundamenta as explicações do seu fracasso, como se dependesse apenas dele o sucesso escolar e o sucesso na vida, desconsiderando os aspectos 
sociais, como se aqueles fossem processos unívocos e lineares. Justifica-se, assim, que são os indivíduos que apresentam dificuldades e não conseguem aprender ou se adaptar às normas sociais de sobrevivência e de possíveis sucessos escolares ou sucessos na vida. Esse tipo de concepção dificulta a luta em prol de uma educação mais igualitária e de qualidade, a partir do momento em que reduz o problema aos indivíduos e que camufla os ideais que corroboram a manutenção do insucesso escolar. E, assim, aumenta-se a distância entre o que há de mais desenvolvido (gênero humano) e indivíduo concreto.

Os resultados do presente estudo indicam que os problemas de comportamento de escolares estão sendo compreendidos a partir de uma perspectiva a-histórica de análise, desconsiderando e naturalizando as relações de produção capitalistas. Garrido e Moysés (2010) discutem que são naturalizadas as desigualdades produzidas socialmente e que sua origem é imputada aos indivíduos, principalmente em suas características biológicas.

A esse propósito, Leontiev (2004) não descarta a teoria das leis biológicas, visto que o homem não está isento de tais influências, porém essas influências não determinam o seu desenvolvimento sócio-histórico, tampouco limitam o desenvolvimento sócio-histórico da humanidade. Não se pode desconsiderar que o indivíduo, como aponta o autor, nasce candidato a se humanizar e que esse processo está atrelado às suas condições socioculturais. Sobre esses aspectos, Vigotski ( 1996 ) expõe que é, por meio da cultura, das relações do sujeito com o mundo que este terá condições de avançar e progredir na direção de um adulto cultural.

Leontiev (2004) assevera que as funções psicológicas superiores são decorrentes das relações humanas no plano social, para, depois, passar para o plano psicológico. $O$ processo de internalização, advindo das operações externas, fruto da inserção de um novo elemento produzido pelo próprio homem, intermediando suas ações, possibilita a passagem de processos interpsíquicos para processos intrapsíquicos.

Nesse sentido, uma criança apenas poderá avançar, em seu desenvolvimento psíquico, se estiver inserida em um contexto sociocultural e com as devidas condições de apropriação da cultura e das potencialidades humanas criadas socialmente. Assim, o homem encontra, na sociedade e nas relações estabelecidas com as pessoas e com o mundo, as aptidões e o saber-fazer, necessários para realizar a atividade mediatizada com a natureza e, então, 
constituir-se em homem cultural. É na relação com os outros homens que o homem se constitui como tal, ao se apropriar da cultura material e não-material (LEONTIEV, 2004).

Desta forma, o homem humaniza-se na cultura e encontra, na educação escolar, as mediações, os instrumentos necessários e fundamentais para o desenvolvimento das funções psicológicas superiores. Essa educação necessita, então, ser de qualidade e ter, como meta, a transmissão e a apropriação dos conhecimentos científicos historicamente produzidos. Entretanto, importa considerar que, na contemporaneidade, vem ocorrendo um esvaziamento dos conteúdos científicos nas escolas, num pragmatismo e relativismo dos mesmos e, não raro, são trabalhados de forma a não permitir a crítica da realidade e da própria condição de sujeitos.

Uma educação escolar cujo foco se distancia da meta da transmissão e apropriação aprofundada dos conteúdos científicos tenderá a fragilizar as possibilidades de desenvolvimento, de sucesso escolar. Podem ser muitas as implicações decorrentes disto, entre as quais, como se vê comumente, está a queixa de que os escolares apresentam problemas de aprendizagem e comportamento nas escolas, sendo muitos deles considerados "portado46 res de distúrbios neurológicos", como Transtorno de Déficit de Atenção e Hiperatividade - TDAH; Transtorno Opositivo e Desafiador - TOD, Transtorno de Conduta, Dislexia, entre outros.

As justificativas para esses transtornos estão marcadamente no indivíduo, visto que são vistas apenas por um viés orgânico, atrelando o desenvolvimento humano quase que exclusivamente ao fator biológico. Essas explicações centralizam-se no sintoma apresentado pela criança e adolescente e partem da concepção de que eles têm, naturalmente, as capacidades de prestar atenção e controlar seus comportamentos, assim, não se avança na direção do entendimento das determinações essenciais em que se revela a ausência do "comportamento e aprendizado adequado". Por outra via, sobressai a necessidade de se compreender como são formadas essas capacidades, enquanto funções psíquicas complexas e especificamente humanas, para então se discutir os peremptórios de um possível desenvolvimento precário das mesmas, que configuraria o déficit de atenção, a dificuldade em centrar a conduta (LEITE; PASQUALINI; EIDT; TULESKI, 2012). 
Parte-se do pressuposto de que a formação dos atos voluntários, do autodomínio da conduta nos estudantes constitui uma conquista do desenvolvimento, do processo educativo, visto que está atrelado ao desenvolvimento das funções psicológicas superiores. Como se vê, esse depende da ampliação e elevação do universo cultural (apropriados por meio dos conteúdos curriculares) além das exigências da vida cotidiana, com a apropriação das potencialidades humanas, criadas socialmente. Destarte, cabe ao ensino escolar (pautado por estrutura, políticas educacionais, sólida formação de professores etc.) se concretizar como intencional e conscientemente dirigido, criando condições promotoras e potencializadoras do desenvolvimento psíquico dos seus alunos, dos atos voluntários em suas máximas possibilidades.

Outro aspecto relevante a ser abordado refere-se ao fato de que, analisando os artigos, verifica-se que aqueles cujos problemas de comportamento eram compreendidos a partir do indivíduo, isto é, do aluno, da família ou do professor, apresentam um alto índice de explicações atribuídas aos alunos $(64,7 \%)$. Esse resultado revela que os problemas de comportamento de alunos estão sendo compreendidos levando em conta a perspectiva de que eles têm suas patologias específicas, necessitando, portanto, de diagnóstico e tratamento, emergindo, daí, os encaminhamentos para psicólogos e médicos; isso, em geral, inclui a psicoterapia e, sobretudo, o uso de medicação.

Como expõe Garrido e Moysés (2010, p. 150), nas últimas duas décadas, tem se aceitado, cada vez mais, a perspectiva de que as dificuldades escolares de nossas crianças decorrem de problemas orgânicos, cuja resolução é de ordem médica. "Essa certeza abre espaço para profissionais da saúde, exames, rótulos, diagnósticos, remédios, todos voltados a legitimá-la e a transformar crianças em crianças-problema ou anormais". São individualizados problemas coletivos, excluindo das explicações e das soluções o próprio processo de escolarização.

De acordo com Collares e Moysés (2010), a criança de "hoje" é difícil de ser ensinada por seus professores, concepção essa que é permeada por juízos prévios. Assim,

[...] as crianças não aprendem porque são pobres, porque são negras, ou por serem nordestinas, ou provenientes da zona rural; são imaturas, são preguiçosas; não aprendem porque seus pais 
são analfabetos, $[\ldots]$ as mães trabalham fora, não ensinam os filhos... (COLLARES; MOYSÉS, 2010, p. 196).

Além disso, as autoras alertam para o perigo em biologizar os "problemas" sociais, pois isso desloca "[...] o eixo de uma discussão político-pedagógica para causas e soluções pretensamente médicas, portanto inacessíveis à educação. A isto, devemos chamar de medicalização do processo ensino-aprendizagem" (COLLARES; MOYSÉS, 2010, p. 197). Isenta-se o contexto escolar como parte dessa produção "[...] criando ou ampliando um novo mercado de trabalho para avaliar, diagnosticar e tratar doenças no processo ensino-aprendizagem" (SOUZA; CUNHA, 2010, p. 225).

Assim, diante da questão por que os alunos continuam na escola, mas não aprendem e não se comportam adequadamente, encontram-se respostas, como nos artigos científicos analisados, em que as ciências psicológicas e pedagógicas se aliam a outras ciências de maneira a utilizar argumentos que tomam o indivíduo como foco e isentam as políticas públicas, a escola.

Assim, são apresentadas as disfunções orgânicas, as incapacidades intelectuais, os problemas emocionais, os comportamentos inadequados, as 48 disfunções neurológicas, a desnutrição, a carência cultural, a desestruturação e a falta de apoio das famílias para com as crianças, entre outros. Tal perspectiva tem como pano de fundo a inadaptação do sujeito à escola e à sociedade, conjecturando pseudoexplicações para a exclusão, entre as quais se encontra a de patologização, que envolve a biologização e a psicologização, imbricadas no cotidiano escolar (MEIRA, 2011 ).

São fabricadas doenças, com soluções medicalizantes em que os interesses da indústria farmacêutica oferecem a cura para elas, para os problemas escolares, submetendo-os ao enquadramento em ideais de normalidade. $\bigcirc$ enfrentamento de tal abordagem "[...] exige ações alternativas em outra direção, que ultrapasse o discurso teórico já consolidado" (GARRIDO; MOYSÉS, 2010 , p. 158).

Defende-se, pois, a importância e a necessidade de abordagens alicerçadas por concepções e ações em prol do processo de emancipação do sujeito em desenvolvimento e que não eximam os professores, pais, políticas educacionais, a escola e a sociedade de suas responsabilidades para com a criança em sua escolarização. Faz-se mister caminhar em direção à superação dessa forma biologizante de se compreender os problemas de comportamento 
de escolares, ampliando-se o olhar, realizando análises mais profundas e, assim, buscando entender as relações que têm produzido esses comportamentos nos alunos.

Constata-se, ainda, que a família foi significativamente exposta nos artigos como justificativa para os problemas de comportamento dos alunos, em uma frequência de $23,5 \%$, sendo que os pais ou responsáveis pela criança são apresentados como os únicos culpados pelos problemas de comportamento, pelo fracasso escolar constituído e entrelaçado, historicamente, em uma trama de relações sociais. Ocultam-se, nessas discussões, em que a família é o centro, as políticas, a ideologia, as diferenças sociais e econômicas que geram desigualdades de oportunidades de inserção e participação nas diferentes instâncias sociais. Desconsidera-se que uma família não se constitui, linearmente, e deslocada do contexto da sociedade da qual faz parte.

Assim, é importante lembrar que os ideais de família (pai, mãe, filhos, avós...) são constituídos em sua diversidade pela/e na sociedade (historicamente). No sistema capitalista, veem-se modelos ser delineados em que, contraditoriamente, são postulados comportamentos e papéis e nem sempre são possibilitadas as devidas condições (de trabalho, de tempo, de informações específicas sobre o desenvolvimento infantil) para que se exerçam as funções normatizadas. Dessa forma, os indivíduos são considerados incapazes, destoantes dos padrões e responsabilizados pelos problemas sociais, pelos problemas escolares.

A culpabilização recai sobre a família da criança, sobressaindo os problemas de relacionamento, as dificuldades de colocação de limites, falta de estrutura familiar, o desinteresse pelo processo de escolarização, como sendo as causas para os problemas de comportamento da criança, bem como seu insucesso escolar. A família torna-se a única explicação para os problemas do cotidiano escolar, constituindo-se em uma concepção unilateral, isentando outras instituições, como a escola e a sociedade, nas análises realizadas.

Todavia, ao se destarcar que Vigotski (1996) aponta as relações sociais como essenciais ao desenvolvimento e aos processos de aprendizagem, não se pode deixar de considerar que esses processos têm início muito antes da entrada da criança na escola, por meio das diversas interações com o entorno social, inicialmente mediadas, principalmente, pela família que as 
alicerçam, em geral, com os conceitos cotidianos, (comuns) que serão "superados" pelos conceitos científicos na educação escolar.

Faz-se mister salientar que a família é uma importante e essencial instituição para o processo de formação do indivíduo, no que tange, entre outros fatores, ao estabelecimento de regras e limites, fatores que fazem parte da estruturação do comportamento da criança. Todavia, embora a família exerça função fundamental nessa formação, isso não deve se caracterizar como exclusividade sua. Há outros fatores envolvidos, o que inclui a participação de outras instituições, tais como: a escola, a religião, a cultura e a própria sociedade.

A escola necessita analisar seu papel na expressão do comportamento dos alunos, estabelecendo um trabalho pedagógico bem direcionado, com professores valorizados, bem preparados e políticas pedagógicas que oportunizem estratégias de solução das dificuldades, presentes no contexto escolar, inclusive em relação aos problemas de comportamento.

$\bigcirc$ professor, como justificativa para as dificuldades de comportamento, aparece em terceiro lugar entre os textos analisados, com um percentual de respostas de $11,8 \%$. Nessa direção, os problemas de comportamento estão diretamente relacionados à ação do professor, às suas dificuldades metodológicas ou técnicas. Aqui, são eleitos outros sujeitos, contudo sob a mesma ótica de naturalização. Os professores são considerados desinteressados, despreparados com práticas pedagógicas inadequadas, desqualificados para o ato de ensinar e, assim, um processo de individualização de um problema coletivo mais uma vez se fortalece. São deslocados de sua inserção profissional, institucional, da sociedade; a instituição escolar fica isenta e os problemas escolares são negados na dialética de suas relações.

Asbahr e Souza (2007) afirmam que as condições concretas de trabatho enfrentadas pelos professores têm provocado a desmotivação, o desgaste físico e emocional. Assim, as ações realizadas na/e pela escola não produzem o resultado esperado; ao contrário, denunciam as políticas pedagógicas que boicotam a sua função, provocando condições de trabalho desumanizadoras, que desautorizam professores e enfraquecem o ensino dos alunos das camadas populares. Tais problemas têm como causa, também, uma formação docente insuficiente e limitada. Nessas condições as ações, e resultados na educação, em nossa realidade, não poderiam mesmo ser muito melhores. 
Defende-se a necessidade de uma formação com consistência teórica, que permita ao professor apropriar-se de novos conhecimentos científicos, fornecendo-the subsídios para, na prática pedagógica, compreender seu importante papel de mediação enquanto sujeito histórico e político que contribui, significativamente, para a constituição de sujeitos, capazes de criar e recriar suas possibilidades de ser alunos, de ser pais, de ser profissionais, engajados com o compromisso de questionar os discursos, os ideais, as práticas instituídas, enfim, de romper com a sociedade de desigualdades.

Saviani (2007) defende a importância de que os ideais prevalecentes (de formação, de ser humano, de comportamento, de aprendizagem, de educação escolar etc.) passem pela confrontação com a prática pedagógica em curso na sociedade atual, visando submeter a uma crítica. Quanto mais o professor e o sistema de ensino forem capazes de compreender os vínculos de suas práticas com a prática social global, mais sua contribuição será eficaz.

Ao vislumbrar o professor na atividade docente, em sua constituição enquanto sujeito humano deve-se compreender que

[...] as leis do desenvolvimento do psíquico do homem estão socialmente condicionadas nas e pelas relações sociais de produção", o que envolve um complexo processo, o qual é determinado pelas condições de vida e educação (AITA; FACCl, 201 1, p. 1).

Ou seja, em atividade, no trabalho e pelo trabalho, conduzido pela e na sociedade a qual pertence e executa o seu trabalho (no caso a capitalista) o professor constitui-se, desenvolve-se, enquanto sujeito singular e universal. Assim, a atividade docente não é expressão apenas da "ação docente", ou seja, da relação ensino-aprendizagem, mas também expressão das relações e condições sociais de produção organizadas na sociedade capitalista, compreendidas em sua totalidade, mediadas por processos educacionais (conhecimentos apropriados e objetivados), por políticas, pela formação docente, por concepç̃oes e relações com a deficiência, dentre outros.

Não se pode isentar o papel fundamental que o professor exerce na aprendizagem e no desenvolvimento do aluno, principalmente ao compreender que o processo de educação é responsável pela apropriação das qualidades humanas. 
Para Facci (2004, p. 135), "[...] o que se espera é que na escola, a aprendizagem se constitua em uma fonte de desenvolvimento dos conceitos científicos, pois ela é o momento decisivo e determinante de todo o desenvolvimento intelectual da criança". A autora defende que, no trabalho educativo, - professor e a escola precisam encaminhar os indivíduos à reflexão sobre os "[...] conhecimentos não cotidianos, como a ciência, a arte, a filosofia, a moral e a política" (FACCl, 2004, p. 68), em uma abertura a outras possibilidades de reflexão e compreensão da sociedade, sobretudo com sua crítica e problematização. A ciência amplia as capacidades psíquicas, bem como a maneira de os sujeitos compreenderem e atuarem sobre o mundo.

Sendo o desenvolvimento cultural da conduta humana revolucionário e produto do meio, ele demonstra quanto a escola pode ser capaz de gerar esta revolução interna, de promover a superação das funções elementares e orgânicas pela formação das funções psíquicas superiores e culturais (TULESKI, 2009, p. 174).

A escola seria a responsável por elevar as crianças a níveis de desenvolvimentos superiores, proporcionando "[...] tarefas cada vez mais complexas 52 para as crianças e, ao mesmo tempo, oferecendo os recursos culturais necessários à resolução destas" (TULESKI, 2009, p. 176). Essa transição das funções elementares às funções psicológicas superiores acontece pela apropriação dos meios - instrumentos e signos, que passam a ser os mediadores para a ação. A autora destaca que a educação exerce um papel revolucionário na vida de uma criança, uma vez que cria uma linha de desenvolvimento cultural e psíquico. A educação escolar pode ser capaz de gerar uma revolução interna, de promover a superação das funções psíquicas elementares em funções psíquicas superiores e culturais.

Este é o desafio do processo de formação dos professores: colaborar para que esses profissionais compreendam sua função na escola, a importância da educação escolar e que ele tenha condições de estabelecer uma relação consciente com o seu trabalho para que compreenda o seu papel com a atividade docente na formação do sujeito, em seu vir-a-ser, como processo contínuo e dialético. É importante que o professor não seja excluído no que tange à compreensão sobre o processo de produção do sucesso/ fracasso escolar, tampouco ser responsabilizado, unicamente, pelo mesmo, 
desvinculando as implicações dialéticas do âmbito social, econômico, cultural, político com a atividade docente.

Apoiados na perspectiva histórico-cultural, compreende-se que o professor precisa ter as condições adequadas de formação inicial e continuada, a apropriação dos conhecimentos científicos que the possibilite realizar as mediações necessárias no processo ensino-aprendizagem. Vale salientar, todavia, que não se pode isentar as responsabilidades do Estado, dos órgãos governamentais, alicerçados por políticas públicas, por investimentos em recursos humanos e físicos do processo educativo, visando a colaborar para que sejam organizadas, intencionalmente, as condições adequadas a fim de proporcionar a máxima apropriação das qualidades humanas pelas novas gerações, e que sejam desenvolvidas oportunidades de sucesso escolar.

\section{Eixo 2 - Problemas de comportamento decorrentes de questões institucionais, políticas, sociais e econômicas: a não centralidade no indivíduo}

Entre os textos analisados, identificam-se aqueles que apresentam uma compreensão dos problemas de comportamento de escolares além de questões individuais, centradas no aluno, família ou professor, e que consideram, em suas análises, aspectos institucionais, políticos, sociais e econômicos. Essa perspectiva, entretanto, ficou restrita a um percentual de 27,6\%. Esse índice não se apresenta como desejável, ainda que não deixe de ter sua relevância, visto que pode produzir movimentações e revela a indicação de que outros olhares e ações estão sendo produzidos. Assim, os estudos, constantes nos artigos, consideram os fatores de ordem institucional, social, econômica e política, anunciando que se deve olhar além da aparência do fenômeno, buscando a sua essência.

Esses artigos superam as explicações reducionistas, que analisam o fenômeno apenas do ponto de vista do indivíduo, envolvendo, em suas perspectivas de compreensão e de análise dos problemas escolares, aspectos muito mais amplos, visando estabelecer relações em que diversos contextos são considerados e as correlações do individual com o universal.

É relevante ressaltar que uma leitura mais crítica sobre o fracasso escolar ocorreu a partir do final de 1980, pois, até esse momento, os problemas, no processo de escolarização, eram analisados e compreendidos apenas numa 
perspectiva do indivíduo, sobretudo do aluno. Nesse movimento, a Psicologia escolar introduz um novo eixo de análise do processo de escolarização, considerando o papel das políticas públicas educacionais na constituição do dia a dia escolar e do aluno que (não) aprende, na relação do professor com a sua tarefa docente, nas condições objetivas que permitem, ou não, que a escola possa exercer as suas finalidades sociais (SOUZA, 2010). É válido refletir, como recomenda a autora, sobre o posicionamento político de compromisso com o excluído, que contempla a necessidade de vislumbrar, além do aluno, as relações deste com a escola e com a sociedade.

Nessa esfera, Meira (201 1) discute a exclusão no sistema educacional brasileiro e revela sua longa história. De início, propagado pela falta de oportunidades de ingresso à escola de amplos contingentes de crianças, sobretudo para as crianças mais pobres, e, mais adiante, em majorados graus de evasão e repetência. $E$, hoje, encontra-se de forma mais sutil, ainda que não menos violenta, ou seja, revela-se com a permanência de crianças e jovens nas escolas por longos períodos. Todavia "[...] nunca chegam a se apropriar de fato dos conteúdos escolares" (MEIRA, 201 1, p. 92). Além disso, não têm avalizados $\circ$ "[...] o sucesso escolar, tampouco o acesso a posições sociais

54 mais elevadas" (MEIRA, 2011 , p. 94). Assim, a aparência igualitária camufla as exclusões que a escola promove e perpetua, impedindo o acesso aos bens culturais, explicada, ideologicamente, na afirmativa: "[...] nem todas as crianças reuniriam as condições necessárias para aprender os conteúdos escolares" (MEIRA, 2011 , p. 94).

Assim, vai configurando o fracasso escolar como decorrente das inadequadas condutas dos alunos, pelas suas dificuldades e não aprendizagem, culminando por legitimar a continuidade do processo de transferência de questões pertencentes ao âmbito da sociedade para a educação, para a atividade docente, destes para a saúde, traduzidos como sendo pertinentes e particulares do aluno que não aprende, do aluno problema, do aluno doente.

Em uma leitura em que se amplia a perspectiva para além da atuação imediata do professor, do campo de sua prática pedagógica, do fazer técnico, do praticismo das questões imediatas, exige-se que sejam analisadas as bases materiais e concretas. Do contrário, os professores estarão sendo desconectados do contexto histórico-social no qual atuam como profissionais docentes, haja vista que assim serão despidos "[...] de sua potencial dimensão político-epistemológica, pois não se transforma em medidas para a efetiva 
elevação do estatuto da profissão professor e para a melhoria das condições escolares" (FACCl, 2004, p. 67).

Nesse aspecto, Basso (1998) afirma que a sociedade não tem propiciado ao professor cumprir a sua função, de forma integral, haja vista que esse profissional, ao se submeter às empresas privadas ou ao Estado burguês, é expropriado de seu trabalho pelo capital, passando a não se desenvolver de maneira plena. "Vimos que a natureza do trabalho docente não tem possibilitado uma maior objetivação do processo de trabalho, deixando margem para a autonomia do professor" (BASSO, 1998, p. 6).

O autor indica ainda que são muitas as condições que propiciam que o trabalho do professor se transforme em um processo cada vez mais degradante e alienante:

Ganhando mal, com uma jornada de trabalho extensa, não deixando tempo disponível para a preparação de aula, a correção de trabalhos e a atualização, poucas oportunidades de discussão coletiva para solucionar problemas do cotidiano escolar, como o professor pode desenvolver um trabalho que tenha interesse para ele próprio e para o aluno? Os professores estão, muitas vezes, realizando uma prática alienante, comprometendo, assim, a qualidade do ensino (BASSO, 1998, p. 7).

Compreender os sujeitos, inscritos como sociais, nos impele à análise de como se forjam determinadas sociedades, as quais são moldadas pelas relações mercantis, constituindo sujeitos nesse vértice. As determinações do fazer-se humano são obtidas pelas relações de produção, as quais não podem ser negadas nas análises, reflexões ou pensamentos que desejam explicá-las, ou seja, "[...] o modo de produção da vida material condiciona o processo de vida social, política e intelectual" (MARX, 2008, p. 47). Isso nos sinaliza o quanto é relevante voltar-se para a educação escolar, sendo ela formadora de sujeitos (trabalhadores, políticos etc.), de sociedade, de cultura, ou seja, dialeticamente, em sua singularidade contribui para a constituição do universal e é constituída por ele; o todo e as partes se inter-relacionam e, contraditoriamente, se delimitam, se ampliam.

Tais compreensões demandam o resgate dos aspectos gerais e particulares da vida concreta para que se tenham os elementos, necessários a uma análise científica. Há a necessidade de abarcar a totalidade da compreensão 
do ser humano, que não separa as condições concretas que produzem a existência do homem. Assim, indivíduo e sociedade não podem ser dissociados; o homem é um ser social, e sua individualidade é abalizada pelas condições que essa mesma sociedade the impõe, bem como o grupo social é determinado pelas condições do indivíduo particular. Tal análise implica, ainda, em trazer à tona, que as condições aplicadas pela sociedade de cada momento da história são assinaladas pelas relações sociais de produção, isto é, pela maneira como o homem produz sua vida; para isso, o trabalho é fundamental.

É possível constatar mudanças na Educação, na Psicologia, com novas perspectivas de vislumbrar os problemas educacionais, com a possibilidade de considerar outras relações, além daquela que envolve o aluno e o conteúdo escolar apropriado ou não. Todavia não se pode deixar de mencionar, como explicam Carvalho e Martins (2011) que ainda se mantém o padrão burguês de indivíduo competente, hábil, empreendedor, competitivo. Assim, torna-se

[...] previsível que em uma sociedade, na qual as condições de vida revelam um quadro contraditório de máxima riqueza e máxima miserabilidade, as crenças na ascensão social e nas conquistas pelo mérito pessoal são necessariamente mantidas (CARVALHO; MARTINS, 2011 , p. 33).

Numa perspectiva diferenciada, crítica, vislumbra-se que mesmo nas relações mais fragmentadas, como na sociedade capitalista, existe o potencial para a transformação das relações. Nesse rol, é preciso que ocorra a desnaturalização das relações sociais e dos fenômenos humanos, que estão fetichizados e alienados, isentando questionamentos das explicações dadas como verdades pelos profissionais, pela ciência. "A busca por uma psicologia que conceba a história humana de forma dialética descortina as relações que excluem os homens da produção da sua vida" (SUZUKI, 2012, p. 99). As relações humanas devem ser consideradas nas ciências como relações históricas.

\section{Considerações finais}

Com base nas análises dos artigos que foram selecionados no presente estudo, foi possível verificar que a maioria deles apresenta uma concepção de problemas de comportamento em escolares numa perspectiva individualizada do fenômeno, com ênfase no aluno, família ou professor. $\bigcirc$ destaque 
na individualização se averigua na exacerbação dos potenciais considerados como inatos, isto é, próprios de cada indivíduo. Assim, evidencia-se que a compreensão que se destaca sobre as dificuldades envoltas no contexto escolar relacionadas aos comportamentos de escolares, relaciona-se, prioritariamente, a aspectos do indivíduo. São vislumbradas, dessa forma, as justificativas situadas ora no professor ora na família e/ou, principalmente no próprio aluno.

$\bigcirc$ estudo revelou que o aluno é culpabilizado pelo seu comportamento inadequado na escola, o que acaba por legitimar o processo de transferência de questões pertencentes ao âmbito da sociedade para a educação, para a atividade docente, destes para a saúde, traduzidos como sendo pertinentes e particulares do aluno que não aprende, do aluno problema, do aluno doente. São feitas análises descontextualizadas, de forma a desconsiderar a totalidade que abarca os problemas no âmbito escolar, sobretudo as relacionadas aos problemas de comportamentos de alunos, isentando, assim, a escola e a própria sociedade de qualquer responsabilidade na produção dessa problemática.

Em face deste resultado, pode-se afirmar que os textos analisados, na sua maioria, não consideram as dimensões sociais e históricas que permeiam todas as relações humanas e que estão envolvidas na produção de um problema no contexto escolar. Ressalta-se que, quando se descartam das análises os determinantes sócio-históricos, torna-se inviável desvendar com precisão o fenômeno em foco, mantendo-se na aparência do sintoma, não evoluindo para a essência do fenômeno e, assim, caindo nas explicações biologizantes e naturalizantes dos problemas de comportamento.

Todavia, os resultados do estudo também apontaram artigos que se distanciam dessa compreensão, com análises sobre o problema de escolares que partem de uma perspectiva que considera aspectos sociais, políticos e econômicos na constituição dos assim denominados problemas de comportamento. Isso evidencia um avanço, embora ainda muito insignificante, para retirar do aluno e de sua família a culpa por um problema bastante complexo e que pode conduzir ao fracasso de muitos.

É essencial desnaturalizar o insucesso escolar, problematizar as relações dialéticas e contraditórias à luz de teorias e práticas, políticas e ações cotidianas, saúde e doença, sociedade e indivíduo etc., buscando os conhecimentos teóricos para as transformações necessárias. Para tanto, devem ser 
favorecidos processos coletivos de reflexão que considerem as condições objetivas imediatas e suas relações com o universal.

\section{Notas}

1 As diferentes grafias para o nome Vigotski seguem como consta na referência utilizada.

\section{Referencias}

AITA, Elis Bertozzi; FACCI, Marilda Gonçalves Dias. Subjetividade: uma análise pautada na psicologia histórico-cultural. In: CONGRESSO NACIONAL DE PSICOLOGIA ESCOLAR E EDUCACIONAL, 10; 2011 , Maringá. Anais... Maringá: Universidade Estadual de Maringá, 2011 . Disponível em: http://www.abrapee.psc.br/xconpe/trabalhos/1/225. pdf. Acesso: maio 2015.

ANUÁRIO Brasileiro da Educação Básica. Todos pela Educação. São Paulo: Editora Moderna, 2017. Disponível em: https://www.todospelaeducacao.org.br//arquivos/ biblioteca/anuario_brasileiro_da_educacao_basica_2017_com_marcadores.pdf. Acesso em: 28 jan. 2017.

58 ASBAHR, Flávia da Silva. Ferreira; SOUZA, Marilene Proença Rebelo. Buscando compreender as políticas públicas em educação: contribuições da psicologia escolar e da psicologia histórico-cultural. In: MEIRA, Marisa Eugênia Melillo; FACCl, Marilda Gonçalves Dias (Org.) Psicologia histórico-cultural: contribuições para o encontro entre a subjetividade e a educação. São Paulo: Casa do Psicólogo, 2007.

BASSO, Itacy Salgado. Significado e sentido do trabalho docente. Caderno CEDES, Campinas, v. 19, n. 44, p. 19-32, abr. 1998.

CARVALHO, Saulo Rodrigues de; MARTINS, Lígia Márcia. A sociedade capitalista e a inclusão/exclusão. In: FACCI, Marilda Gonçalves Dias; MEIRA, Marisa Eugênia Melillo; TULESKI, Silvana Calvo (Org.). A exclusão dos "incluídos": uma crítica da psicologia da educação à patologização e medicalização dos processos educativos. Maringá: Eduem, 2011.

CHIZZOTTI, Antônio. Pesquisa em ciências humanas e sociais. 7. Ed. São Paulo: Cortez, 2005.

COlLARES, Cecilia Azevedo Lima; MOYSÉS, Maria Aparecida Affonso. Preconceitos no cotidiano escolar: a medicalização do processo ensino-aprendizagem. In: CONSELHO REGIONAL DE PSICOLOGIA DE SÃO PAULO (Org.). Medicalização de crianças e 
adolescentes: conflitos silenciados pela redução de questões sociais a doença de indivíduos. São Paulo: Casa do Psicólogo, 2010.

FACCI, Marilda Gonçalves Dias. Valorização ou esvaziamento do trabalho do professor: um estudo crítico-comparativo da teoria do professor reflexivo, do construtivismo e da psicologia vigotskiana. Campinas: Autores Associados, 2004.

GARRIDO, Juliana; MOYSÉS, Maria Aparecida Affonso. Um panorama nacional dos estudos sobre a medicalização da aprendizagem de crianças em idade escolar. In: CONSELHO REGIONAL DE PSICOLOGIA DE SÃO PAULO (Org.). Medicalização de crianças e adolescentes: conflitos silenciados pela redução de questões sociais a doença de indivíduos. São Paulo: Casa do Psicólogo, 2010.

KLEIN, Lígia Regina; SILVA, Graziela Lucchesi Rosa da; MATA, Vilson Aparecido da. Alienação ou exclusão: refletindo o processo de "inclusão" na educação de jovens e adultos. In: FACCl, Marilda Gonçalves Dias; MEIRA, Marisa Eugênia Melillo; TULESKI, Silvana Calvo (Org.). A exclusão dos "incluídos": uma crítica da Psicologia da Educação à patologização e medicalização dos processos educativos. Maringá: Eduem, 2011.

LEITE, Hilusca Alves; PASQUALINI, Juliana; EIDT, Nadia Mara; TULESKI, Silvana Calvo. A desatenção medicalizada: uma questão a ser enfrentada pela psicologia e educação. In: BARROCO, Sônia Mari Shima; LEONARDO, Nilza Sanches Tessaro; SILVA, Tânia dos Santos Alvarez da (Org.). Educação especial e teoria histórico-cultural: em defesa da humanização. Maringá: EDUEM, 2012.

LEONTIEV, Alexis Nikolaievich. O desenvolvimento do psiquismo. Tradução Hellen Roballo, 2. Ed. São Paulo: Centauro, 2004.

MARX, Karl. Contribuição crítica da economia política. 2. Ed. São Paulo: Editora Expressão Popular, 2008.

MEIRA, Marisa Eugênia Melillo. Incluir para continuar excluindo: a produção da exclusão na educação brasileira à luz da Psicologia Histórico-Cultural. In: FACCl, Marilda Gonçalves Dias; MEIRA, Marisa Eugênia Melillo; TULESKI, Silvana Calvo. (Orgs.) A exclusão dos "incluídos": uma crítica da Psicologia da Educação à patologização e medicalização dos processos educativos. Maringá: Eduem, 2011.

MEIRA, Marisa Eugênia Melillo. Para uma crítica da medicalização na educação. Psicologia Escolar e Educacional, Campinas, v. 1, n. 1, p. 135-142, jan./jun. 2011.

SAVIANI, Demerval. Do senso comum à consciência filosófica. 15. Ed. Campinas: Autores Associados, 2007. 
SOUZA, Marilene Proença Rebelo. Retornando à patologia para justificar a não aprendizagem escolar: a medicalização e o diagnóstico de transtornos de aprendizagem em tempos de neoliberalismo. In: CONSELHO REGIONAL DE PSICOLOGIA DE SÃO PAULO (Org.). Medicalização de crianças e adolescentes: conflitos silenciados pela redução de questões sociais a doença de indivíduos. São Paulo: Casa do Psicólogo, 2010.

SOUZA, Marilene Proença Rebelo; CUNHA, Beatriz Belluzzo Brando. Projetos de Lei e políticas públicas: o que a psicologia tem a propor para a Educação? In: CONSELHO REGIONAL DE PSICOLOGIA DE SÃO PAULO (Org.). Medicalização de crianças e adolescentes: conflitos silenciados pela redução de questões sociais a doença de indivíduos. São Paulo: Casa do Psicólogo, 2010.

SUZUKI, Mariana Akemi. A medicalização dos problemas de comportamento e de aprendizagem: uma crítica social de controle. $2012.174 f$. Dissertação (Mestrado em Psicologia) - Programa de Pós-Graduação em Psicologia, Universidade Estadual de Maringá, 2012.

TULESKI, Silvana Calvo. Vygotski: a construção de uma psicologia marxista. Maringá: Edvem, 2009.

VIGOTSKI, Lev Semyonovich. Teoria e método em psicologia. Tradução /Claudia Berlini. São Paulo: Martins Fontes, 1996.

VIGOTSKII, Lev Semyonovich; LURIA, Alexander Romanovich; LEONTIEV, Alexis Nikolaievich. Linguagem, desenvolvimento e aprendizagem. Tradução Maria da Pena Villalobos. 12. Ed. São Paulo: ĺcone, 2014.

VIGOTSKY, Lev Semyonovich. A construção do pensamento e da linguagem. Tradução Paulo Bezerra. 2. Ed. São Paulo: Martins Fontes, 2009.

Prof. ${ }^{a}$ Dr. ${ }^{a}$ Nilza Sanches Tessaro Leonardo Universidade Estadual de Maringá Departamento de Psicologia Programa de Pós-Graduação em Psicologia Grupo de Pesquisa Psicologia Histórico-Cultural e Educação E-mail: nilza_sanches@yahoo.com 
Prof. ${ }^{a}$ Dr. ${ }^{a}$ Zaira Fátima de Rezende Gonzalez Leal Universidade Estadual de Maringá

Departamento de Psicologia

Programa de Pós-Graduação em Psicologia Grupo de Pesquisa Psicologia Histórico-Cultural e Educação

E-mail: zairagleal@gmail.com

Prof. ${ }^{a}$ Dr. ${ }^{a}$ Solange Pereira Marques Rossato Universidade Estadual de Maringá Departamento de Psicologia Grupo de pesquisa Psicologia Histórico-Cultural e Educação E-mail: solmarques@hotmail.com

Recebido 28 maio 2018 Aceito 22 jun. 2018 